\title{
Assessment on the Operation and Strategy amidst the Covid-19 Pandemic: Case of National Power Corporation (NAPOCOR)
}

\author{
Engr. Joefil C. JOCSON ${ }^{1}$, Engr. Ryan John L. DE LARA ${ }^{2}$, Engr. Christopher M. LADIGNON ${ }^{3}$, Engr. Zol D. \\ MEDINA $^{4}$, Engr. Melissa R. MEDINA ${ }^{5}$, Engr. Joeme Carl DEMEGILLO ${ }^{6}$ \\ 1,2,3,4,5,6 Nueva Ecija University of Science and Technology, Gen. Tinio Street Cabanatuan City 3100
}

\begin{abstract}
The Covid-19 pandemic brought enormous challenges in the business operations of the world. With these, the National Power Corporation (NPC) range of services around the Philippine archipelago faced enormous challenges. In this study, the assessment of the strategy in the operations of the National Power Corporation (NPC) to the procurement division of the institution was considered. To discuss the result of this study, a descriptive research was used. The respondents were chosen using random sampling technique. The respondents typically carried the title of Division Manager, Engineer I, Engineer II, Admin Services, Information Assistant, and Logistics Management Officer. The survey questionnaires measure the capability and support of the company considering the Covid-19 pandemic situation. The survey questionnaires were encoded and distributed electronically using Google Forms. In addition to this, follow-up interviews were also made to the randomly selected employees and clientele of the Procurement Division of the NPC.

After conducting survey and follow-up interviews, the results clearly shows that it is possible for the key personnel of the Procurement Division to conduct, continue, and deliver its mandates, functions, duties and responsibilities using an alternative work arrangement such as a work-from-home scheme and it made the department operational. The findings on the support of the company also show positive results. It indicates that the company's strategy during the pandemic is noticeable and well-implemented. The new structure developed by the company according to the respondents can also be used even after the pandemic.
\end{abstract}

\section{KEYWORDS: Covid-19 Pandemic, Operations, Strategy, National Power Corporation}

\section{INTRODUCTION}

National Power Corporation (NPC) a government-ownedand controlled corporation mandated to energize far flung, off-grid areas and islands in the Philippines. The NPC currently operating 275 Small Power Utilities Group (SPG) plants in 238 areas in 198 municipalities acres the 34 provinces of the Philippines. Additionally, to the SPG Plant the NPC likewise operate the power assets such as the 981 MW Agus and Pulangi Hydroelectric Power Plants in Mindanao (www.napocor.gov.ph).

The novel coronavirus disease, also referred to as COVID-19, was first identified in December 2019 in the city of Wuhan, which is in the Hubei province of China. Within a short time, the COVID-19 epidemic spread throughout the globe, becoming a true pandemic that has severely affected almost every country (Wagner, 2020). COVID19 pandemic brought enormous challenges in the business operations of the world. However, people were able to re-think and reanalyze the strategic tools and responds to the need of business/ establishments/ institutions. With these, the National Power Corporation (NPC) range of services around the Philippine archipelago faced enormous challenges. Nonetheless, the NPC were able to re-evaluate and formulate strategies and implementation in short term and long-term solution for the new normal operations. Hence, this this study, particularly focus on assessment of the strategy in the operations of the National Power Corporation (NPC) to the procurement division of the institution.

\section{OBJECTIVE OF THE STUDY}

The general objective of the study was to assessed operation and strategy in the procurement division of the National Power Corporation (NPC) in response with the COVID -19 pandemic. The following specific objectives:

Specific objectives

1. To determine a simple demographic profile of the respondents.

2. To determine the capability of the key employees from procurement to function in their respective duties and responsibilities in new normal situation.

3. To determine the effectiveness of the strategy developed in the operation of the procurement division into the delivery of its functions. 


\section{MATERIALS AND METHODOLOGY}

\section{Conceptual Framework}

A descriptive research study was used to discuss the results of this study. In Figure \#\# shows the conceptual framework of the study. Initial sets of questions were prepared in order to attain the main of objective of the study to assess the operation and strategy of National Power Corporation particularly in the Procurement Division. The questionnaire were encoded and distributed electronically using the Google Forms. Additionally, an interview were made to follow-up questions to the randomly employees and clientele of the Procurement Division of NPC. The lists of questionnaires show in Annex.

\section{Sample}

The data used in this study were obtained from a survey conducted on some employees of the National Power Corporation, specifically under the Procurement Unit.

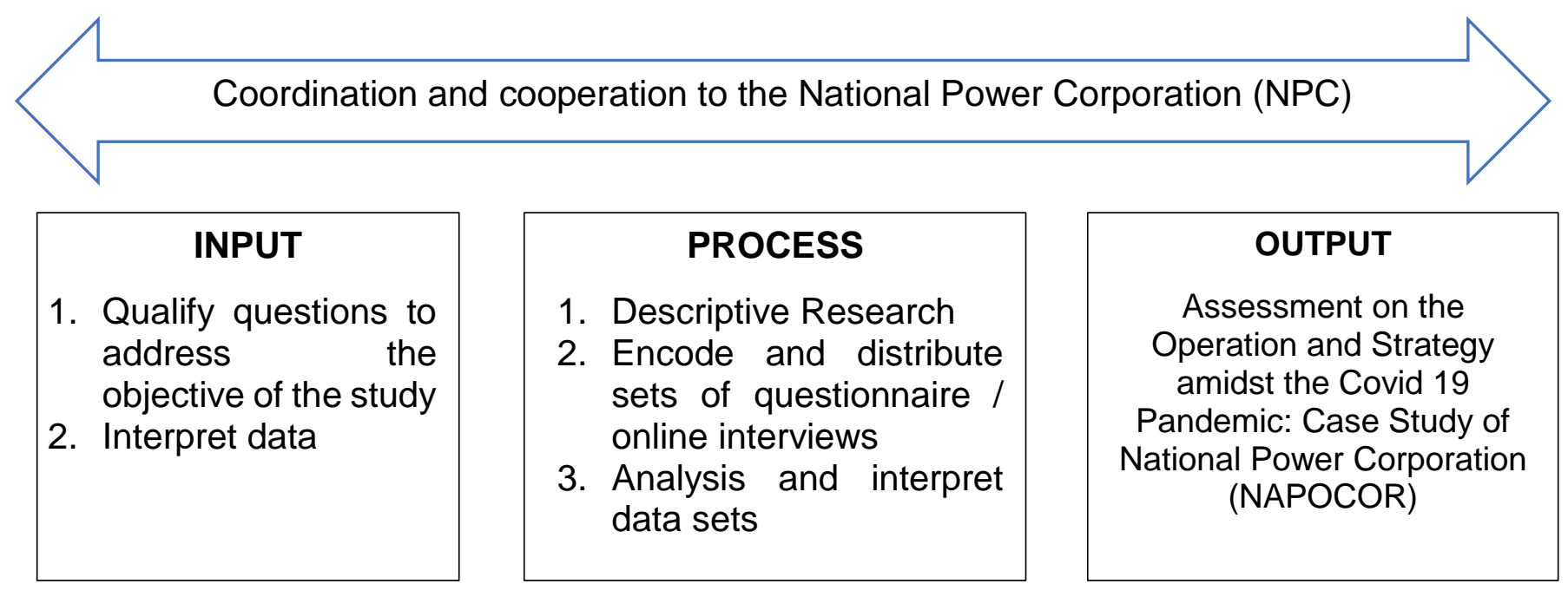

Figure 1. Conceptual Framework of the Study

\section{Questionnaire Survey}

The survey questionnaire used in this study was based on the current situation, where we are under the situation of the pandemic due to the Covid-19. The survey was conducted online and the questionnaire was accompanied by a statement indicating the purpose of the study and assurance of the complete confidentiality of the respondents. Additionally, to encourage participation, the respondents were promised that the responses will be compiled together and analyzed as a group. The respondents typically carried the title of Division Manager, Engineer I, Engineer II, Admin Services, Information Assistant, and Logistics Management Officer.

The survey questionnaire specifically measures the following:

a. Measures for the capability of the company. The capability of the company to work under high absenteeism of workers was measured. Also, the capability of the company or concerned unit to perform under a remote working scheme was measured, in relation to the current situation caused by the Covid-19.

b. Measures for the support of the company. In order for the employees to perform their duties efficiently and for the department to perform its tasks, there must be support coming from the company. This is the reason why there is a need to measure if the company is providing necessary support to its employees especially in this time of the pandemic.

\section{RESULTS AND DISCUSSION}

The conducted survey will determine the measures implemented by the company in relation to the pandemic caused by the Covid-19, the strategies implemented by the company in order to support its employees and to continue the delivery of its services. Tables 1,2 , and 3 will show the profile of the respondents.

TABLE 1. Profile of Respondents According to Gender

\begin{tabular}{|l|l|l|}
\hline Gender & Male & Female \\
\hline Percentage of Respondents & $45.45 \%$ & $54.55 \%$ \\
\hline
\end{tabular}


"Assessment on the Operation and Strategy amidst the Covid-19 Pandemic: Case of National Power Corporation (NAPOCOR)"

TABLE 2. Profile of Respondents According to Age

\begin{tabular}{|l|l|l|l|l|l|}
\hline Age Bracket & $18-25$ & $26-35$ & $36-45$ & $46-55$ & $56-65$ \\
\hline Percentage of Respondents & $18.18 \%$ & $45.45 \%$ & $0 \%$ & $18.18 \%$ & $18.18 \%$ \\
\hline
\end{tabular}

TABLE 3. Profile of Respondents According to Position Title

\begin{tabular}{|l|l|}
\hline Position Title & Percentage \\
\hline Division Manager & $9.09 \%$ \\
\hline Engineer II & $18.18 \%$ \\
\hline Engineer I & $18.18 \%$ \\
\hline Logistics Manager Officer & $18.18 \%$ \\
\hline Information Assistant & $9.09 \%$ \\
\hline Administrative Officer & $9.09 \%$ \\
\hline Financial Management System-A & $9.09 \%$ \\
\hline Admin Services Assistant & $9.09 \%$ \\
\hline
\end{tabular}

The tables show the profile of the respondents. The respondents are composed of $54.55 \%$ female and $45.45 \%$ male. Almost $50 \%$ of the respondents' age falls under the bracket of 26 years old to 35 years old, $18.18 \%$ from the bracket of 18 years old to 25 years old, and $18.18 \%$ also from the bracket of 56 years old to 65 years old. Additionally, the respondents carried the title of Division Manager, Engineer I, Engineer II, Admin Services Assistant, Information Assistant, Financial Management System-A, and Logistics Management Officer.

TABLE 4. Capability of Department to Operate

\begin{tabular}{|r|l|l|}
\hline CAPABILITY OF DEPARTMENT TO OPERATE & Yes & No \\
\hline $\begin{array}{l}\text { 1. Can your department operate with 25\% or greater absenteeism } \\
\text { of personnel? }\end{array}$ & $81.80 \%$ & $18.20 \%$ \\
\hline $\begin{array}{l}\text { Can your department operate with 50\% or greater absenteeism } \\
\text { of personnel? }\end{array}$ & $72.70 \%$ & $27.30 \%$ \\
\hline $\begin{array}{l}\text { Can your department operate with 70\% or greater absenteeism } \\
\text { of personnel? }\end{array}$ & $54.50 \%$ & $45.50 \%$ \\
\hline 4. Can employees work remotely? & $63.60 \%$ & $36.40 \%$ \\
\hline 5. If illness causes high absenteeism, can other employees \\
perform other duties? & $90.90 \%$ & $9.10 \%$ \\
\hline $\begin{array}{l}\text { Can your department function effectively through long-term } \\
\text { remote working? }\end{array}$ & $45.50 \%$ & $54.50 \%$ \\
\hline $7 . \quad$ Are the employees empowered or trained to work from home? & $63.60 \%$ & $36.40 \%$ \\
\hline
\end{tabular}

The results clearly show that the department can function and operate even with a high percentage of absenteeism and it indicates that employees can perform their functions working remotely. The results also show that an alternative work arrangement such as a work-from-home scheme will make the department operational. A remarkable high percentage of $90.90 \%$ shows that the employees of the department are well-trained, such that they can even perform other tasks not related to their specific duties. But when it comes to long-term remote working, $54.50 \%$ of the respondents said that the department can't function effectively through long-term remote working.

TABLE 5. Support Provided by the Company to its Employees

\begin{tabular}{|c|l|l|l|}
\hline SUPPORT OF THE COMPANY & Yes & No \\
\hline $\begin{array}{l}\text { 1. } \\
\text { Does the company present a model or memorandum for alternative work } \\
\text { arrangements to ensure that all employees are following the protocol and } \\
\text { health standards while ensuring the operation of the company is continuous? }\end{array}$ & $100 \%$ & $0 \%$ \\
\hline $\begin{array}{l}\text { 2. } \\
\text { Does the company consider the welfare of the employees in this time of } \\
\text { pandemic? }\end{array}$ & $100 \%$ & $0 \%$ \\
\hline 3. Does the company develop a new structure for the operation of the \\
department in relation to the pandemic?
\end{tabular}




\begin{tabular}{|c|c|c|}
\hline $\begin{array}{l}\text { 4. If the company developed a new structure for the operation, does it make the } \\
\text { procedures simpler and easier for the employees and the customers? }\end{array}$ & $81.80 \%$ & $18.20 \%$ \\
\hline $\begin{array}{l}\text { 5. Are the new procedures for transactions of the company simpler and can be } \\
\text { done remotely? }\end{array}$ & $63.60 \%$ & $36.40 \%$ \\
\hline $\begin{array}{l}\text { 6. Is there a digital training platform for the employees provided by the } \\
\text { company to prepare them for alternative work arrangements? }\end{array}$ & $54.50 \%$ & $45.50 \%$ \\
\hline $\begin{array}{l}\text { 7. Is there an improvement with the connectivity or IT system of the company, } \\
\text { enough to handle simultaneous transactions? }\end{array}$ & $81.80 \%$ & $18.20 \%$ \\
\hline $\begin{array}{l}\text { 8. Does the company develop a new helpline to manage access control and } \\
\text { communications? }\end{array}$ & $63.60 \%$ & $36.40 \%$ \\
\hline $\begin{array}{l}\text { 9. Are there well-coordinated and standardized communication systems and } \\
\text { protocols to ensure clear and transparent communication with all } \\
\text { stakeholders? }\end{array}$ & $90.90 \%$ & $9.10 \%$ \\
\hline $\begin{array}{l}\text { 10. Does the company have an existing risk reduction management team that } \\
\text { functions to mitigate the risks within the company? }\end{array}$ & $90.90 \%$ & $9.10 \%$ \\
\hline $\begin{array}{l}\text { 11. For employees under the work from home scheme, does the company } \\
\text { provide additional support like internet allowance, etc. for them to perform } \\
\text { their tasks efficiently? }\end{array}$ & $9.10 \%$ & $90.90 \%$ \\
\hline $\begin{array}{l}\text { 12. For employees required to perform their tasks in the office, does the company } \\
\text { provide support such as traveling expenses or company service vehicles to } \\
\text { ensure the safety of the employees? }\end{array}$ & $90.90 \%$ & $9.10 \%$ \\
\hline $\begin{array}{l}\text { 13. Does the newly developed structure for the operation of the company can } \\
\text { also be used even after the pandemic? }\end{array}$ & $90.90 \%$ & $9.10 \%$ \\
\hline
\end{tabular}

The findings on the support of the company also show positive results. It indicates that the company's strategy during the pandemic is noticeable and well-implemented. The results show that the company first disseminated a memorandum for the new model or alternative work arrangements in relation to the current situation, the pandemic caused by the Covid-19. The welfare of the employees is the one being considered by the company. With the new setting for work being developed, the company assured that the procedures are simpler and easier for the employees and customers, making it possible to work remotely.

To ensure that the employees can perform their duties well through the new work arrangement, $54.50 \%$ of the respondents said that the company provided them training on the applications of the digital platform. Since most of the transactions will be entertained online, the management also improved the internet connectivity or the IT system of the company capable of handling multiple transactions. Even though the management was not able to provide additional support such as internet allowance for employees working from home, the management ensures the safety of the employees working at the office by providing support such as traveling allowance and service vehicles. There is also an existing risk reduction management team that helps mitigate the possible risks within the company. Lastly, the new structure developed by the company according to the respondents can also be used even after the pandemic.

\section{CONCLUSION}

This research aimed to determine the measures implemented by the corporation in relation to the administrative support services workforce as a strategy in the pandemic caused by the Covid-19. To provide administrative and technical support in the proponent processing of the requirements of the corporation. Based on a quantitative and qualitative analysis of intention in response to the survey questionnaire how it is can be concluded that implementation of a skeletal/work-from-home scheme is a possible and effective process. The results indicate that proponent personnel is more receptive to continue to provide procurement process by the use of technology and other logistics methodology while there are limitations on the operation of its decision.

Based on the results of the survey questionnaire, the following conclusions were drawn:

1. It is possible and doable for the key personnel of the procurement division, Logistics Department to conduct, continue and deliver its mandates, functions, duties, and responsibilities on the procurement process by other alternatives workforce schedule under the new normal with this Covid-19 pandemic.

2. The effectiveness of the strategy developed in the operations of the division was manifested by the results of their outputs.

3. The impact on the delivery of services as a result of this research can be determined also on the individual personnel key result areas vis-a-vis key performance indicators on the actual versus targets work plan of the division. 
"Assessment on the Operation and Strategy amidst the Covid-19 Pandemic: Case of National Power Corporation (NAPOCOR)"

\section{REFERENCES}

1. Wagner, G. S. (2020). Natural history of COVID19 and Current Knowledge on treatment therapeutic options.

https://doi.org/10.1016/j.biopha.2020.110493

2. https://www.napocor.gov.ph/

3. https://www.gartner.com/smarterwithgartner/10questions-for-an-hr-pandemic-plan/
4. https://www.ey.com/en_gl/covid-19/covid-19crisis-management-essential-ten-better-questions$\underline{\text { to-ask }}$

5. https://martechseries.com/content/digi-assetmgmt/50-questions-ask-test-preparednesspandemic-induced-lockdown/ 